\title{
Cetacean behavioral responses to noise exposure generated by seismic surveys: how to mitigate better?
}

\author{
Clara Monaco ${ }^{1,2,{ }^{\star}}$, Jesús M. Ibáñez ${ }^{3,4}$, Francisco Carrión ${ }^{3,4}$, L. Mario Tringali ${ }^{1}$ \\ ${ }^{1}$ Ketos Cultural Scientific Association, Catania, Italy \\ ${ }^{2}$ Università di Catania, Dipartimento di Agricoltura, Alimentazione e Ambiente, Catania, Italy \\ ${ }^{3}$ Instituto Andaluz de Geofisica, Universidad de Granada, Granada, Spain \\ ${ }^{4}$ Istituto Nazionale di Geofisica e Vulcanologia, Sezione di Catania, Osservatorio Etneo, Catania, Italy
}

\author{
Article history \\ Received January 12, 2016; accepted June 3, 2016. \\ Subject classification: \\ Seismic surveys, Cetaceans, Behavioral responses, Monitoring, Mitigation protocol.
}

\begin{abstract}
Cetaceans use sound in many contexts, such as in social interactions, as well as to forage and to react in dangerous situations. Little information exists to describe how they respond physically and behaviorally to intense and long-term noise levels. Effects on cetaceans from seismic survey activities need to be understood in order to determine detailed acoustic exposure guidelines and to apply appropriated mitigation measures. This study examines direct behavioral responses of cetaceans in the southern Mediterranean Sea during seismic surveys with large airgun arrays (volume up to 5200 ci) used in the TOMO-ETNA active seismic experiment of summer 2014. Wide angle seismic and multi-channel seismic surveys had carried out with refraction and reflection seismic methods, producing about 25,800 air-gun shots. Visual monitoring undertaken in the 26 daylights of seismic exploration adopted the protocol of the Joint Nature Conservation Committee. Data recorded were analyzed to examine effects on cetaceans. Sighting rates, distance and orientation from the airguns were compared for different volume categories of the airgun arrays. Results show that cetaceans can be disturbed by seismic survey activities, especially during particularly events. Here we propose many integrated actions to further mitigate this exposure and implications for management.
\end{abstract}

\section{Introduction}

Seismic surveys used for monitoring reserves of fossil-fuel and also to study tectonics and dynamics of the seafloor crust, are anthropogenic noise sources that may interfere with natural functions of cetaceans, producing different behavioral reactions in relation to the context, the species and their sex or age [Gordon et al. 2004; Hildebrand 2005].

Marine mammals have a great ability to perceive biologically important sounds in water, but this capacity is endanger in presence of acoustic disturbance human-generated that significantly contribute to noise in the marine environment.

Seismic surveys are characterized by intermittent sound pulses that are more intense than the continuous noise emitted by most industrial noises in the ocean, with peak frequency bands overlapping those used by cetacean in many contexts, such as in social interactions, as well as to forage and in dangerous situations [Finneran et al. 2000; Southall et al. 2007; Heide-Jørgensen et al. 2013].

Noise generated by seismic surveys may overlap with the low frequency sounds of baleen whales, masking long distance communication between individuals and precluding the detection of other feeble sounds [Evans and Nice 1996]. Moreover odontocetes generally show some form of avoidance during survey operations by vacating the area [Stone and Tasker 2006; Castellote et al. 2012]. Temporal avoidance of cetaceans could be also a consequence of avoidance reaction of fish during seismic surveys. These factors may induce in cetaceans different stress responses and behavioral alterations [Gordon et al. 2004] but little information exists to describe how they respond physically and behaviorally to intense and long-term noise levels. Strengthen mitigation measures and investigate their effectiveness is an urgent need to safeguard cetaceans and the entire marine environment. Effects from seismic survey activities need to be better understood in order to regulate detailed acoustic exposure guidelines and to apply mitigation measures appropriated to species and areas of investigation. For this reason, direct observation is very important to detect cetaceans and take action when necessary. Visual monitoring can ensure that the source is shut down whenever an animal is observed within or 
about to enter the safety zone, furthermore it allows to understand behavioral boundaries of a population in relation to the space, the environment and certain life functions that can result in response to a losing access to its optimal conditions [Stone 2000; Beckman 2012; Stone 2015]. Observing cetaceans during seismic surveys is essential to develop precautionary approaches in order to undertake these, following appropriate regulations as mitigation measures. Dedicating right effort and tools to monitor populations it is possible to collect important information on animals, improving the capability to understand phenomena, predict potential effects, and minimize impacts in the future [Stone 2015; Castellote and Llorens 2016]. Comparing different behavioral responses during periods of airguns-firing and periods when airguns are silent allow also investigating short-term responses [Gordon et al. 2004].

In summer 2014, the Granada University (Spain) and the National Institute of Geophysics and Volcanology (INGV) - Section of Catania (Italy), in collaboration with the Italian Navy and other academic institutions, conducted the active seismic experiment TOMO-ETNA which has foreseen seismic surveys on eastern Sicily and Aeolian Islands (Italy) in order to investigate tectonic structures extending from the southern Tyrrhenian Sea towards the Ionian Sea and their interaction with the Etna volcano plumbing system. The research

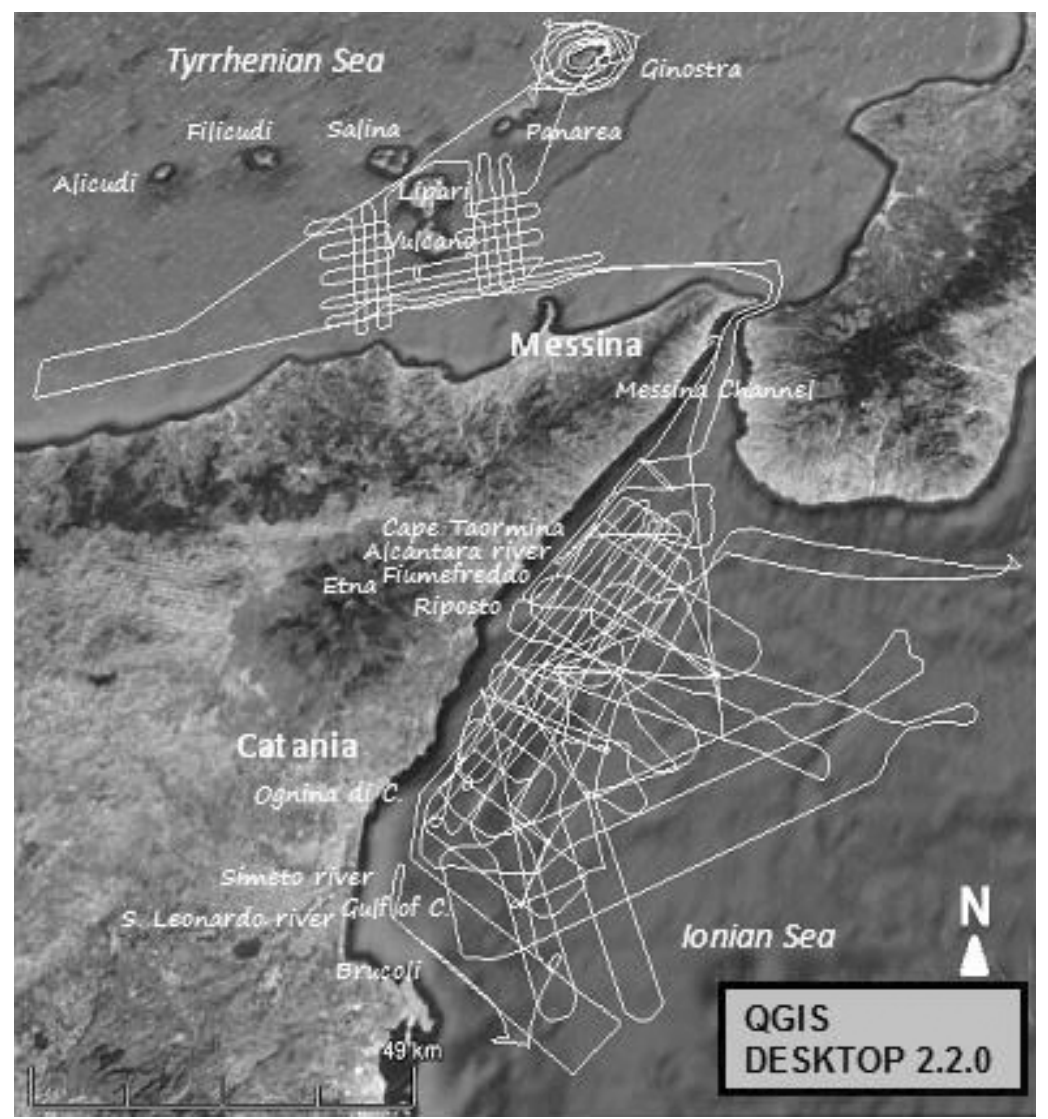

Figure 1. Map of the area under study with covered transects. was included in the MEDiterranean SUpersite Volcanoes (MED-SUV) and EUROFLEETS-2 European projects [Coltelli et al. 2016, in this volume; Ibáñez et al. 2016a, 2016b, in this volume].

In this study, we examine data recorded during the TOMO-ETNA research cruise in order to investigate further the effects of seismic airgun activity on cetaceans. The expedition has provided both shooting times and moments with airguns silent, so it was possible to compare the different phases of firing occurred.

\section{The area}

Transects carried out for the research have affected the Ionian Sea, closeness to the eastern coast of Sicily, and the southern Tyrrhenian Sea, in the Aeolian Islands area (Figure 1). These zones have a high level of primary and secondary productivity despite they are subjected to a strong anthropogenic impact deriving from human activities such as different categories of fishing, coastal engineering, marine traffic, waste and litter dumping, causing habitat alteration, resources over-exploitation and noise pollution [Halpern et al. 2008; Vindigni et al. 2016].

Thermosalinograph parameters recorded in the period June 25 - July 18, 2014, on board the "Sarmiento de Gamboa" oceanographic vessel (CSIC-UTM, Spain), indicate the following minimum and maximum values of water in Ionian and Tyrrhenian Sea: sigma T 25-27.5 sinU; salinity 37.1-38.2 psu; temperature 19.2-26. ${ }^{\circ} \mathrm{C}$.

From the morphological point of view, the area is highly heterogeneous. Within the volcanic archipelago of the Aeolian Islands a number of submarine secondary eruptive centers rise from depths ranging between -400 and -1100 $\mathrm{m}$. Submerged shelves are also located along the western flanks of Vulcano and Lipari, the western and northern flanks of Alicudi, the north-eastern and the south-western flanks of Stromboli, on the whole submerged summit of Panarea and in most of the coastal sector of Filicudi and Salina. Narrower insular shelf borders the islands coastline (down to 100-120 m b.s.l.). An irregular seabed is characterized by alternating ridges and gullies that extend to -2000 $\mathrm{m}$ depth, and depressions bound by escarpments and shallow-water saddle with minimum depth at $-50 \mathrm{~m}$ that connects different volcanic edifices. In the Aeolian Arc are also recognizable outcropping volcanic features and prod- 


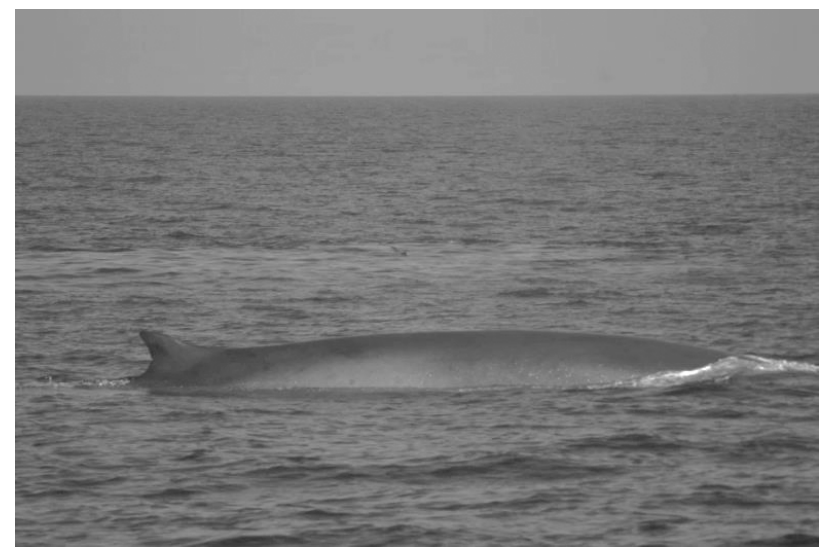

Figure 2. Fin whale during survey in Ionian Sea. (Photo by Ketos association).

ucts of recent submarine eruptive activity. However, smaller-scale mass-wasting processes on the submarine flanks of all the islands contribute to transport large amounts of volcaniclastic sediments towards the base of the volcanic edifices [Romagnoli et al. 2013].

After the semi-enclosed basin of the Messina Channel reaching up to $-1000 \mathrm{~m}$ of depth, on the Ionian side, from Cape Taormina to Riposto, the coast is characterized by pebble beaches interposed with bays and inlets in which imposing calcareous cliffs run out. Here, the continental shelf is almost absent and the bottom slopes steeply down to $-100 \mathrm{~m}$ within a mile from the coast. The central region, up to Ognina di Catania, presents high depths closeness its jagged coastline composed by vulcanites and igneous rocks. Because of a large continental shelf, the southern area of the Gulf of Catania is distinguished by the wide sandy strip of the Playa littoral zone and shallow-water with maximum depth at $-20 \mathrm{~m}$ until 3 miles from the coast.

The platform has a narrow and elongated shape, it slopes quietly up to about $-90 \mathrm{~m}$, beyond the slope increases. In the far south of the area, close to Brucoli, the continental shelf shrinks and limestone cliff of the carbonatic Hyblean Plateau prevails. Offshore the Gulf of Catania the bottom extends from -1000 to -2000 $\mathrm{m}$ depth. The variety of environments described, in particular the presence of a reduced continental shelf and submarine canyons in the Tyrrhenian Sea; the rivers that flow into the Ionian Sea (Alcantara, Fiumefreddo, Simeto, San Leonardo); upwelling and currents that arise from hydrodynamic phenomena that occur in the Messina Channel, involving Aeolian water and generating a residual flow in favor of the eastern coast of Sicily; positively affect the biological richness of the area and help to maintain an equitable distribution of marine life during the year [Amore et al. 1982; Cognetti et al. 2008; Carrà et al. 2014].

This, together with the other factors, favours also the presence of coastal and pelagic species of cetaceans, some of which are presents in the International Union for Conservation of Nature (IUCN) red list and are protected by many international agreements such as the Agreement on the Conservation of Cetaceans in the Black Sea Mediterranean Sea and Contiguous Atlantic Area (ACCOBAMS; 1996), the Habitats Directive (Council Directive 92/43/EEC of May 21, 1992), the Convention on the Conservation of Migratory Species of Wild Animals (Bonn Convention or CMS; 1979), the Convention on the Conservation of European Wildlife and Natural Habitats (Bern Convention; 1979), the Convention for the Protection of the Mediterranean Sea Against Pollution (Barcelona Convention; 1976), the Convention on International Trade in Endangered Species of Wild Fauna and Flora (Washington Convention; 1975), the United Nations Environment Programme (UNEP; 1972).

Fin whale (Balaenoptera physalus; Figure 2) is present along the north and eastern coasts of Sicily, especially during the summer period, because of the passage through the Strait of Messina [Tringali et al. 2008; Sciacca et al. 2015]. Bottlenose dolphin (Tursiops truncatus; Figures 3 and 4) occupies the whole coastal strip, partly in conjunction with the striped dolphin (Stenella coeruleoalba) that makes also daily offshore migrations. In the proximity of the continental slope there

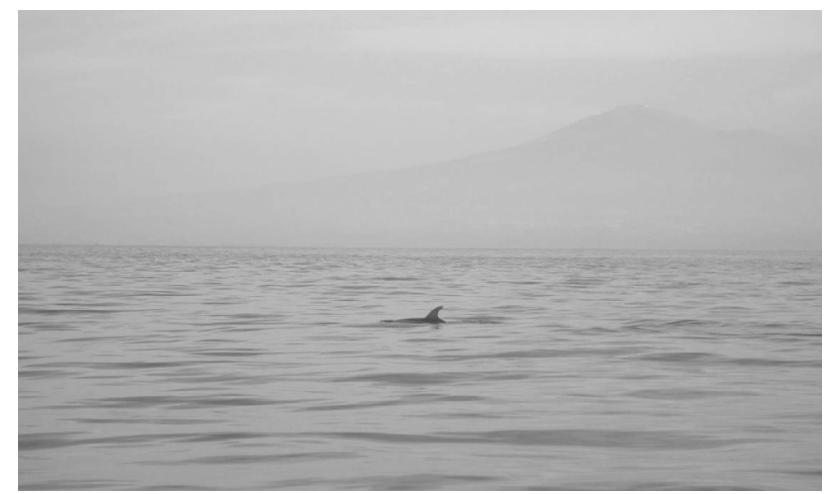

Figure 3. Bottlenose dolphin in the Gulf of Catania with Etna volcano shape. (Photo by Ketos association).

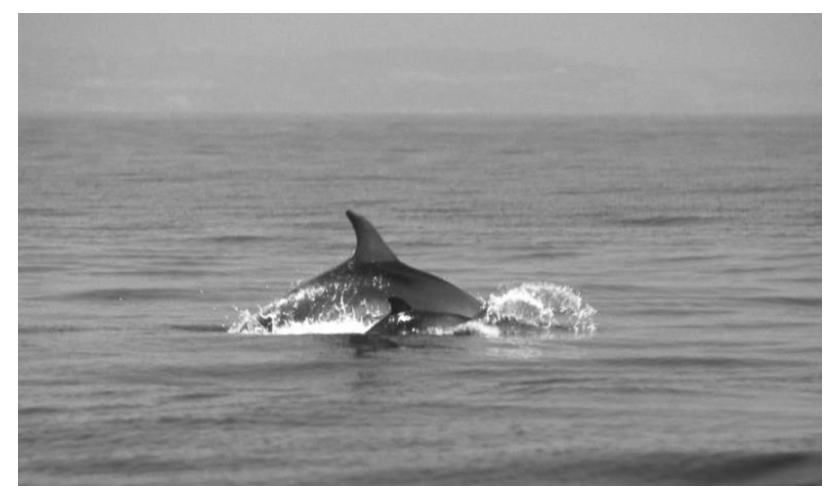

Figure 4. Bottlenose dolphin mother and cub in Ionian sea during summer. (Photo by Ketos association). 
are the Risso's dolphin (Grampus griseus; Figure 5), the Cuvier's beaked whale (Ziphius cavirostris) and rarely also the pelagic common dolphin (Delphinus delphis; Figure 6) [Tringali et al. 2008] but most present in Aeolian region. Bioacoustics data of the National Institute for Nuclear Physics (INFN-LNS) demonstrate the presence of sperm whale (Physeter macrocephalus; Figure 7) all year round, especially offshore [Internullo et al. 2008; Caruso et al. 2015].

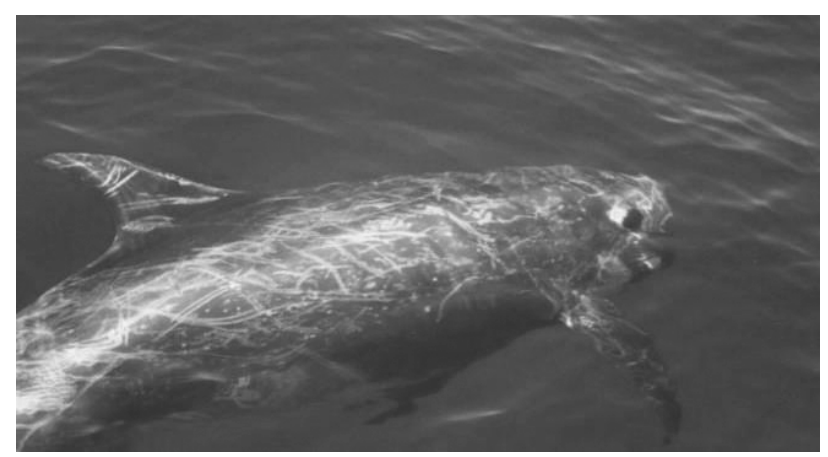

Figure 5. Risso's dolphin during survey offshore the Gulf of Catania. (Photo by Ketos association).

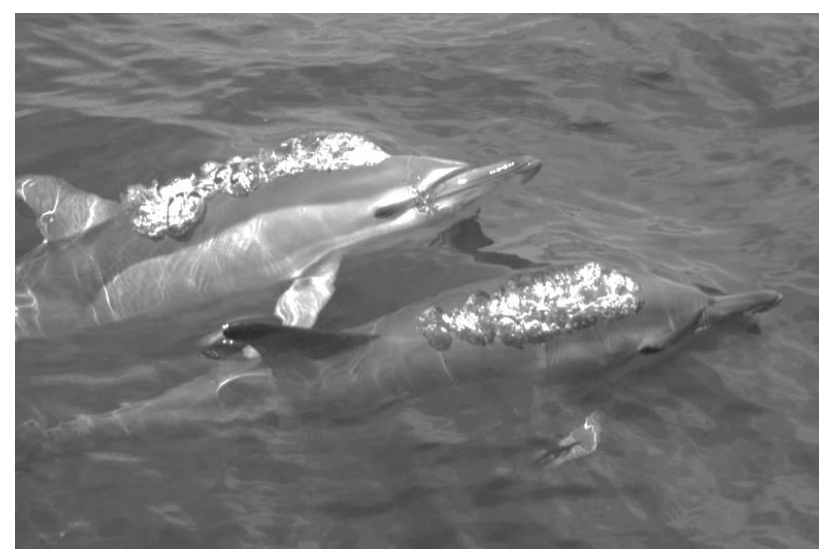

Figure 6. Common dolphins during survey in Ionian Sea. (Photo by Ketos association).

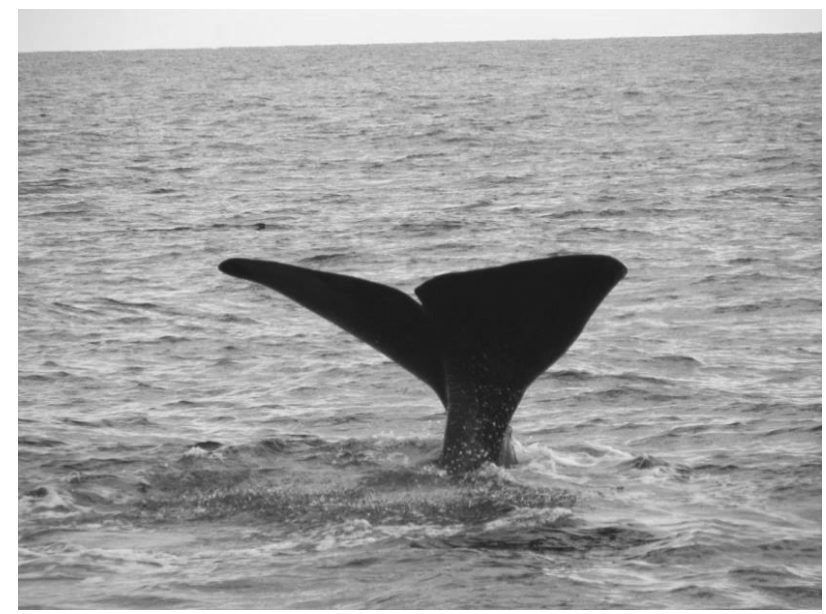

Figure 7. Sperm whale during survey offshore the Gulf of Catania. (Photo by Ketos association).

\section{Methodology}

Data were collected during the TOMO-ETNA experiment where seismic explorations at Etna volcano's roots and surrounding areas were conducted from June 24 to July 20, 2014.

The seismic survey vessel "Sarmiento de Gamboa" using airguns to release pulses of compressed air into the water column, was capable to determine substrata structure due to the creation of sound pressure waves capable to penetrate the seafloor. The escaping component of the generated compressed air contains energy converted to sound thereby generating a seismic signal capable to travel into the Earth's surface.

The research required wide angle seismic (WAS) and multi-channel seismic (MCS) surveys using refraction and reflection seismic methods. Airguns had a total volume up to 5200 cubic inches generated at about 2000 p.s.i. $(1.382 \times 107 \mathrm{~Pa})$ pressure. The array was composed by two batteries, each having 8 guns (Sercel, GGUN II). During WAS surveys they were kept at a depth of $15 \mathrm{~m}$ below the sea level and the shots were carried every 90 seconds. For MCS surveys the depth was $7,5 \mathrm{~m}$ and the range shots 20 seconds [Ibáñez et al. 2014; Ibáñez et al. 2016a, 2016b, this volume].

During 26 survey days on board the vessel, we conducted visual marine mammals monitoring, traveling at a speed of less than 5 knots. Observations were aimed to ensure the implementation of the Joint $\mathrm{Na}$ ture Conservation Committee (JNCC) guidelines, in order to reduce the potential risk of injury or death to cetaceans in close proximity to blasting operations to negligible levels.

Before the start of the experiment, the scientific team (mainly students and geophysicists), has been subjected to an anonymous questionnaire in order to understand their degree of experience in cetacean monitoring. Consequently, some lessons about the implementation of the JNCC guidelines, data recording and marine mammal identification have been given. Therefore one experienced marine biologist, with the support of the members that have received training, carried out visual monitoring by naked eye and using binoculars.

All days, observers, located simultaneously on bridge deck and weather decks of the survey vessel, conducted observational scans covering a range of $360^{\circ}$ during daylight and in good sea condition $(\leq 3$ of the Douglas scale). An observation survey was completed recording data on time, survey vessel (position, route, speed, seismic activity), weather conditions (sky, visibility, sea, wind, precipitation), water (temperature, salinity), marine traffic and notes (presence of animals, large litter, fishing gears, buoys, etc.). These informa- 
tion were recorded at the beginning and at the end of the observation activity, hourly, and each time a change occurred. Furthermore vessel position was track automatically and continuously by the GPS integrated system on-board. During cetacean sightings the Ad libitum sampling method [Altmann 1974; Mann 1999] was applied adding information on time and position (coordinates, distance, radial angle and direction of swim from the vessel). Therefore an additional survey was completed collecting data on species, group size, presence of juveniles, behavior (approaching, leaving, indifferent towards the vessel, surface behavioral patterns according with Shane et al. [1986], Weaver [1987] and Monaco [2006]), other vessels, airguns status, associations with other animals or human activities. Sightings have been recorded in order to understand any behavioral response to seismic surveys. For this reason, changes in volume of airguns arrays have been classified according to Table 1 for identifying any ambiguous or avoidance reaction comparing airguns power shooting. Distance and orientation from the airguns were also compared for different powers of the airguns. Data on cetacean occurrence were also analyzed using the percentage of encounter (number of sighting case for each behavioral category $* 100 /$ total number of sighting case during a specific seismic activity) as sighting rate.

\section{Results}

During the 26 survey days, 2454 nautical miles were covered, generating approximately 24,800 airgun blasts. On about 180 hours of observation we sighted about 400 individuals during 21 sighting of identified species (1, Balaenoptera physalus; 1, Physeter macrocephalus; 1, Ziphius cavirostris; 3, Tursiops truncatus; 15, Stenella coeruleoalba).

Sightings often lasted few seconds or minutes and

\begin{tabular}{|c|c|c|c|}
\hline CODE & BEFORE & \multirow{10}{*}{ 点 } & AFTER \\
\hline AA & High power shooting & & High power shooting \\
\hline AR & High power shooting & & Medium power shooting \\
\hline AD & High power shooting & & Airguns turned off \\
\hline SS & Soft start & & Soft start hold steady \\
\hline SR & Soft start & & Lower Soft start \\
\hline SD & Soft start & & Airguns turned off \\
\hline DS & Airguns turned off & & Soft start \\
\hline DD & Airguns turned off & & Airguns turned off \\
\hline SA & Medium power shooting & & High power shooting \\
\hline
\end{tabular}

Table 1. Classification of power changing events of noise source.

frequently animals were at far distance. Furthermore the geo-scientific team was not very specialized to distinguish cetacean species. Consequently, a lot of animals ( $51 \%$ of total sightings) were not classified by species ( 2 sighting of unidentified big cetaceans and 24 unidentified small cetaceans).

Sighting rates for fin whales, sperm whales and $\mathrm{Cu}$ vier's beaked whale did not decrease when airguns were off despite they were on, but, considering their normal aerial of distribution, a general avoidance of the area was remarked. Instead, cetacean sightings at low distance from the vessel increase when airguns were turned off (Figure 8). During seismic shooting, smaller odontocetes appeared to be feeding; often when they were closed to the vessel, within the 500-meter mitigation zone (MZ), they seemed to swim faster moving away.

The percentage of encounter calculated in good sea conditions (sea state $\leq 3$ of the Douglas scale) increase

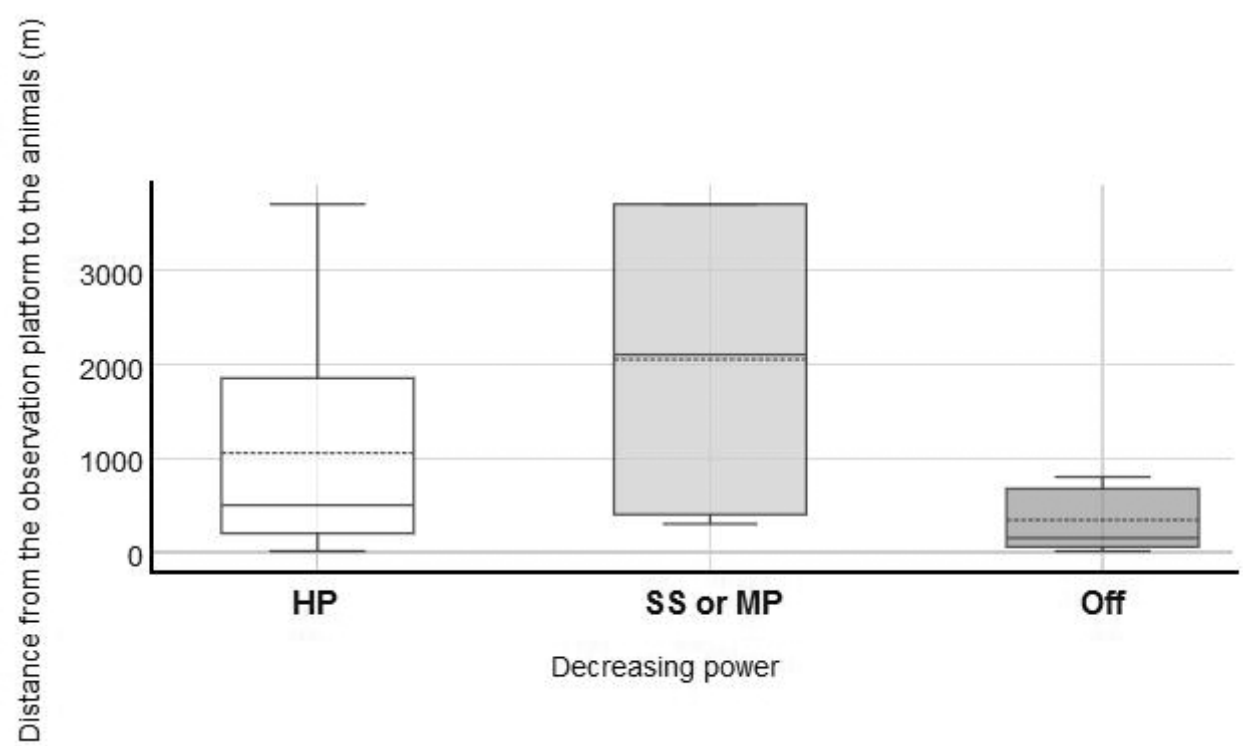

Figure 8. Distance sighting in relation to airguns power. $\mathrm{HP}=$ high power; $\mathrm{SS}=$ soft start; $\mathrm{MP}=$ medium power; Off $=$ source off. 


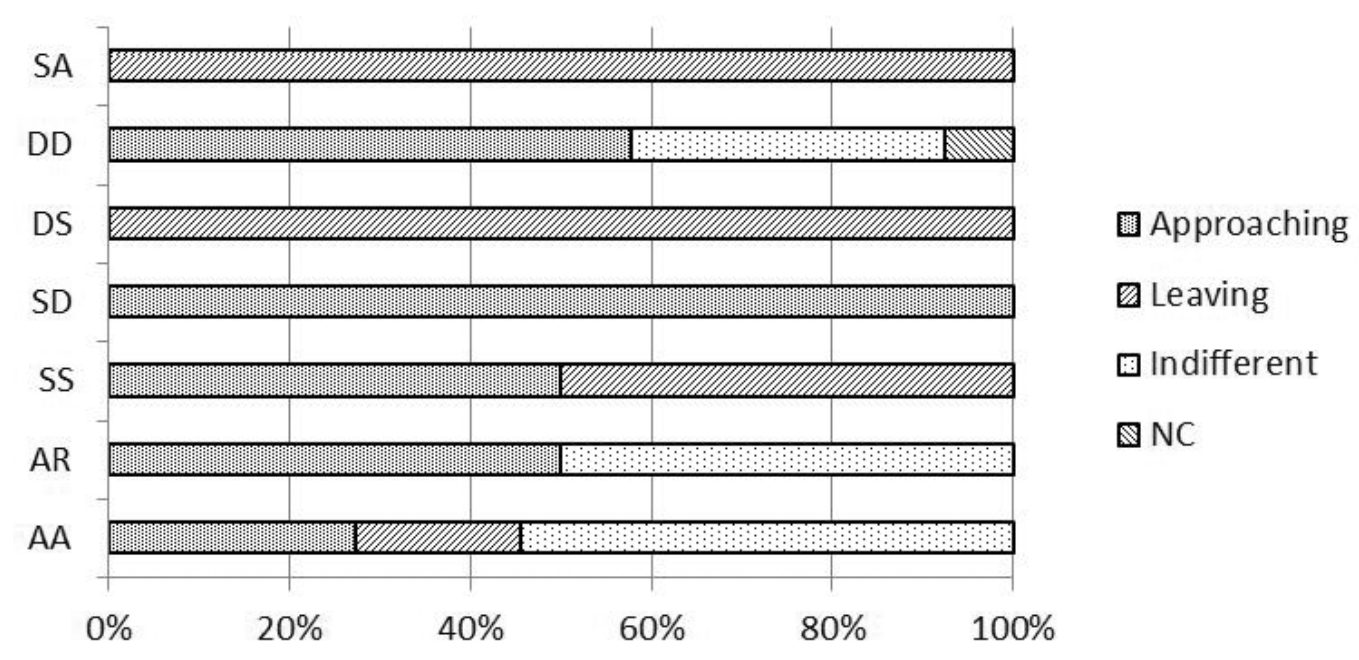

Figure 9. Cetacean responses within the $500 \mathrm{~m} \mathrm{MZ}$, according with classification on power changing in Table 1.

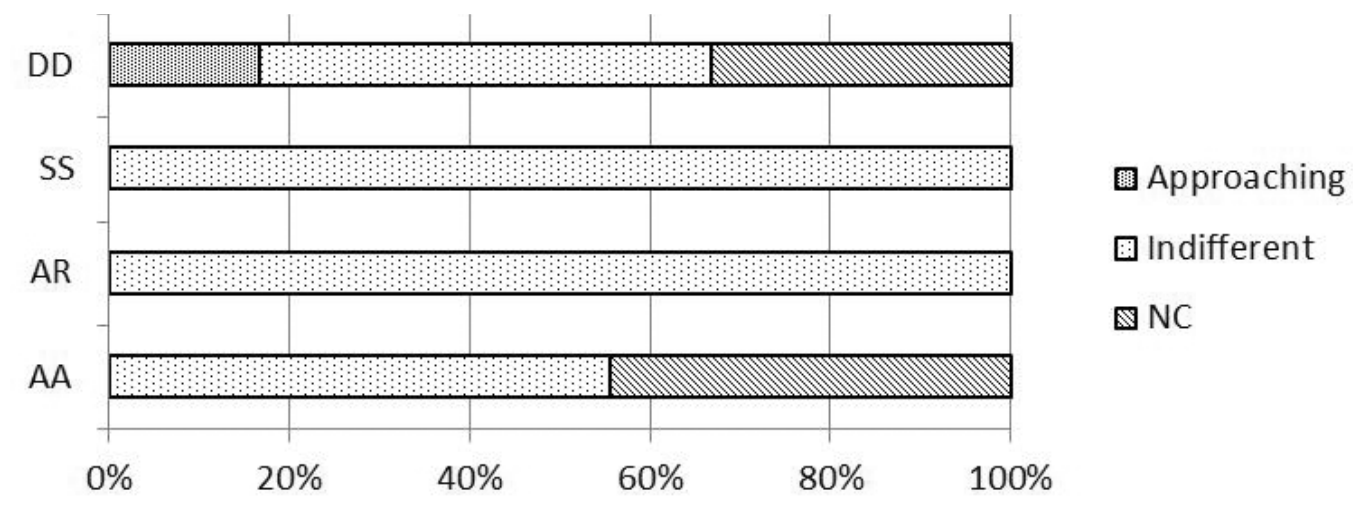

Figure 10. Cetacean responses beyond the $500 \mathrm{~m} \mathrm{MZ}$, according with classification on power changing in Table 1.

with reducing volume ( 0.53 cases with airguns off; 0.24 with airguns on). Furthermore, during the soft start (SS) or other phases with medium power shooting (MP) animals travelled towards the vessel or adopted an indifferent behavior (Figures 9 and 10).

Big cetaceans probably vacate the area during exposure to seismic since contemporary marine mammal surveys, made in proximate areas, verified the presence of fin whales. In fact, phone and radio communications on cetacean occurrence come from the Navy, fisherman, pleasure boaters and local research organizations (Ketos association, MPAs).

Smaller odontocetes may remain in the area but increasing their distance from the noise in relationship to their activities, e.g., small cetaceans were observed during feeding several times in the same zone. Probably, they have not completely avoided the area in order to continue to respond to their life needs, anyway remaining at a certain distance from the noising source.

It is important to underline that the JNCC protocol doesn't prevue power changing of airguns in presence of cetaceans as the SA event reported in Table 1, that is a variation of the volume from medium power shooting to high power shooting. This recorded episode occurred during a line turn phase that, normally, was realized as a SS. In this case, because of a bad communication between the observers on the bridge deck and technicians in the control's room, when four small odontocetes were approaching the vessel, airguns volume was modified from $1700 \mathrm{ci}$ to $3000 \mathrm{ci}$ and then to $4000 \mathrm{ci}$, so dolphins have disappeared immediately.

We highlight that during seismic activities and in months after their end no stranding occurred [Podestà et al. 2015]. Ketos, the local research association that since 1997 studies cetaceans of the investigated area, had also continued its monitoring activities to control cetacean population dynamics and their potential long-term responses to noise exposure (results will be showed in other studies).

\section{Discussion}

Since seismic surveys are used not only for academic researches but ever more mainly by oil companies to find and monitor reserves of fossil-fuel, is important to establish standardized plans to mitigate better impact from generated noise.

Existing protocols were not applied in all the oceans and not always the implemented strategies are adapted 
to survey areas.

However, appropriately conducted long-term monitoring studies were strongly recommended in order to investigate cetacean populations and to measure, with standardized methods, effects deriving from seismic surveys and in general from noise pollution.

Results of this study, according with other works, show that cetaceans can be disturbed by seismic exploration [Hermannsen et al. 2015]. Seeing as behavioral responses to noise exposure can be also highly variable and context dependent, on-board mitigation measures represent the primary method to protect them.

Based on the TOMO-ETNA experience and on the dynamics that usually emerge within seismic studies, here we suggest some potential broader measures for cetacean protection in order to mitigate better impacts of noise exposure during next seismic surveys.

\section{The protocol}

- Marine mammal mitigation guidelines should be adopted by all types of research that require use of airguns. Whilst alternative seismic technologies must be developed.

- It is needed that each Country recognizes the critical importance of precautionary on-board mitigation measures, regulating with laws and mandatory protocols access to their marine areas.

- The start of firing activities must be always preceded by a SS event. The period of increasing power shooting must provide all the intermediate possible volume of airguns during not less than 20 minutes.

- In case of cetacean sighted within the MZ when air guns are firing, the source must be shut-down immediately. If animals leave the security area after more than 5 minutes, new firing activities have to be preceded by a full SS that require also a pre-firing observation.

\section{Marine mammal observers (MMOs)}

- MMOs must be specialized and motivated. They have to monitor during firing activities with shifts of 1-2 hours to avoid excessive fatigue of the observer and without stopping monitoring when guns are firing. Monitoring has to be realized also during pre-firing phases.

- Every MMO must have available essential personal equipment such as binocular and radio to communicate directly with the crew working on the firing.

- A minimum of four MMOs should be simultaneously in observation; they must cover a range of $360^{\circ}$.

\section{Passive acoustic monitoring}

- Visual monitoring should be integrated with passive acoustic monitoring (PAM) by specialized operators.

- When PAM is not possible, the number of spe- cialized MMOs must be increased in the morning and firing activities must be stopped at night or during adverse weather conditions (Douglas sea state $\geq 4$, heavy rain or fog).

\section{Adapted measures}

- Seismic surveys must be approved by supporting scientific basis, as it has been the case in this experiment TOMO-ETNA. At the same way, duration of the prefiring observation and extent of the $M Z$ should be increased according with species distribution and migration in proximity of the surveys areas, with particularly attention to critical habitats.

Only if national and international authorities recognize seismic airgun noise as a serious marine environmental pollutant, it will be possible to apply ad hoc actions and mitigation measures for cetacean conservation. Divulgation of works on seismic surveys is necessary to encourage their intervention.

Acknowledgements. This paper has been partially funded by the following research projects: the European project MED-SUV funded by the European Union's Seventh Framework Program for research, technological development and demonstration under grant agreement No. 308665; the Spanish COCSABO project (COCDI-2011-08); the European project EUROFLEETS2 (Seventh Framework Programme, grant agreement No. 312762) through transnational access to the research vessels "Sarmiento de Gamboa" operated by CSIC (Spain) and "Aegaeo" by HCMR (Greece); the Geophysical Instrument Pool Potsdam (GIPP) from GFZ (Potsdam) with the project (Seismic TOMOgraphy of ETNA volcano and Eolian Islands, Italy, using active and passive seismic data). We would like to thank the following supporting institutions: Dipartimento Regionale della Protezione Civile, Regione Siciliana; Dipartimento Azienda Regionale Foreste Demaniali, Ufficio Provinciale di Catania; Ente Parco dell'Etna; Unidad de Tecnología Marina-CSIC in Barcelona (Spain); Stato Maggiore Marina (Italian Navy General Staff), CINCNAV (Command in Chief of the Fleet) and Marisicilia (Navy Command of Sicily); Coastal Guard of Messina and Riposto; to obtain support and navigation permissions for the oceanographic cruises: Spanish Foreign Office and Italian Foreign Office. This paper has been partially supported by the Spanish projects TEC2015-68752-R (MINECO/FEDER), KNOWAVES and CGL2015-67130-C2-2. This manuscript has been largely improved by the insightful comments of Dr. Arcangeli and De Domenico by the editor José Morales.

\section{References}

Altmann, J. (1974). Observational study of behavior: sampling methods, Behaviour, 49(3). 227-266.

Amore, C., G. Cantone, A. Castagna, B. Costa, I. Di Geronimo, G. Fassari, F. Sarro and F. Sinatra (1982). Primi dati sui popolamenti bentonici, sui sedimenti e sulle caratteristiche fisico-chimiche delle acque del Golfo di Catania, Naturalista Siciliano, 6, Suppl. 3, 547-552.

Beckman, D. (2012). Marine Environmental Biology and Conservation, Jones \& Bartlett Publishers. 
Carrà., G., C. Monaco, I. Peri, C. Prato, F. Safonte F. and G. Vindigni (2014). Rapporto Intermedio Progetto DIVERSO: DIVERsificazione delle attività di pesca e SOstenibilità delle zone costiere della Sicilia, Regione Siciliana, DiGeSA.

Caruso, F., V. Sciacca, G. Bellia, E. De Domenico, G. Larosa, E. Papale, C. Pellegrino, S. Pulvirenti, G. Riccobene, F. Simeone, F. Speziale, S. Viola and G. Pavan (2015). Size Distribution of Sperm Whales Acoustically Identified during Long Term Deep-Sea Monitoring in the Ionian Sea, PLoS ONE 10(12), e0144503.

Castellote, M., C.W. Clark and M.O. Lammers (2012). Acoustic and behavioural changes by fin whales (Balaenoptera physalus) in response to shipping and airgun noise, Biological Conservation, 147, 115-122.

Castellote, M., and C. Llorens (2016). Review of the effects of offshore seismic surveys in cetaceans: are mass strandings a possibility?, In: The Effects of Noise on Aquatic Life II, Springer, New York, 133-143.

Cognetti, G., M. Sarà and G. Magazzù (2008). Biologia Marina, publ. by Calderini, Bologna (Italy).

Coltelli, M., et al. (2016). The marine activities performed within the TOMO-ETNA experiment, Annals of Geophysics, 59(4), S0428, doi:10.4401/ag-7081.

Evans, P.G.H., and H. Nice (1996). Review of the effects of underwater sound generated by seismic surveys on cetaceans, Report to UKOOA, Sea Watch Foundation, Oxford, $50 \mathrm{pp}$.

Finneran, J.J., C.E. Schlundt, D.A. Carder, J. Clark, J.A. Young, J.B. Gaspin and S.H. Ridgway (2000). Auditory and behavioral responses of bottlenose dolphins (Tursiops truncatus) and a beluga whale (Delphinapterus leucas) to impulsive sounds resembling distant signatures of underwater explosions, Journal of the Acoustical Society of America (JASA), 108(1), 417-431.

Gordon, J., D.C. Gillespie, J. Potter, A. Frantzis, M.P. Simmonds, R.R. Swift and D. Thompson (2004). A review of the effects of seismic surveys on marine mammals, Marine Technology Society Journal, 37(4), 16-34.

Halpern, B.S., S. Walbridge, K.A. Selkoe, C.V. Kappel, F. Micheli, C. D’Agrosa, J.F. Bruno, K.S. Casey, C. Ebert, H.E. Fox, R. Fujita, D. Heinemann, H.S. Lenihan, E.M.P. Madin, M.T. Perry, E.R. Selig, M. Spalding, R. Steneck and R. Watson (2008). A global map of human impact on marine ecosystems, Science, 319(5865), 948-952.

Heide-Jørgensen, M.P., R.G. Hansen, K. Westdal, R.R. Reeves and A. Mosbech (2013). Narwhals and seismic exploration: Is seismic noise increasing the risk of ice entrapments?, Biological Conservation, 158,
50-54.

Hermannsen, L., J. Tougaard, K. Beedholm, J. NabeNielsen and P.T. Madsen (2015). Characteristics and propagation of airgun pulses in shallow water with implications for effects on small marine mammals, PloS one, 10(7), e0133436.

Hildebrand, J.A. (2005). Impacts of Anthropogenic Sound, In: J.E. Reynolds, W.F. Perrin, R.R. Reeves, S. Montgomery and T.J. Ragen (2005). Conservation beyond crisis, The Johns Hopkins University Press, Baltimore, Maryland, 101-124.

Ibáñez, J.M., D. Patanè, M. Coltelli, F. Carrion, P.P. Bruno, O. Cocina, L. Zuccarello, A. Díaz-Moreno, J. Prudencio, F. Bianco, D. Cavallaro, M. Firetto Carlino, C. Carmisciano, L. Cocchi, G. D’Anna, B. Lühr and TOMO-ETNA working group (2014). TOMOETNA: an active seismic experiment at Etna volcano, A. Rittman Conference, October 29-31, 2014, Nicolosi, Italy.

Ibáñez, J.M., J. Prudencio, A. Díaz-Moreno, D. Patanè, G. Puglisi, B.-G. Lühr, F. Carrión, J.J. Dañobeitia, M. Coltelli, F. Bianco, E. Del Pezzo, T. Dahm, V. Willmott and V. Mazauric (2016a). The TOMO-ETNA experiment: an imaging active campaign at Mt. Etna volcano. Context, main objectives, working-plans and involved research projects, Annals of Geophysics, 59(4), S0426, doi:10.4401/ag-7079.

Ibáñez, J.M., et al. (2016b). TOMO-ETNA experiment at Etna volcano: activities on land, Annals of Geophysics, 59(4), S0427, doi:10.4401/ag-7080.

Internullo, E., F. Zardin, G. La Manna, G. Riccobene and G. Pavan (2008). Do sperm whales regularly pass from the gulf of Catania? Evidence from 2 years of data collected within the NEMO project, 22nd European Cetacean Society (ECS), 2008.

Mann, J. (1999). Behavioral sampling methods for cetaceans: a review and critique, Marine mammal science, 15(1), 102-122.

Monaco, C. (2006). Studio preliminare sul comportamento di una popolazione di Tursiops truncatus (Montagu, 1821) residente nell'area del Golfo di Catania, Master's thesis, University of Catania.

Podestà, M., B. Cozzi, M. Giurisato, G. Pavan and S. Mazzariol (2015). Cetacean presence in the Italian waters of the Mediterranean Sea based on strandings analysis 1986-2014, 21st Conference on the Biology of Marine Mammals, San Francisco (USA), December 2015.

Romagnoli, C., D. Casalbore, G. Bortoluzzi, A. Bosman, F.L. Chiocci, F. D’Oriano, F. Gamberi, M. Ligi and M. Mariani (2013). Bathy-morphological setting of the Aeolian Islands, Geological Society, London, Memoirs, 37(1), 27-36. 
Sciacca, V., F. Caruso, L. Beranzoli, F. Chierici, E. De Domenico, D. Embriaco, P. Favali, G. Giovanetti, G. Larosa, G. Marinaro, E. Papale, G. Pavan, C. Pellegrino, S. Pulvirenti, F. Simeone, S. Viola and G. Riccobene (2015). Annual Acoustic Presence of Fin Whale (Balaenoptera physalus) Offshore Eastern Sicily, Central Mediterranean Sea, PLoS ONE 10(11), e0141838.

Shane, S.H., R.S. Wells and B. Wursig (1986). Ecology, behaviour and social organization of bottlenose dolphin: a rewiew, Marine Mammal Science, 2(1), 34-63.

Southall, B.L., A.E. Bowles, W.T. Ellison, J.J. Finneran, R.L. Gentry, C.R. Greene, D. Jr. Kastak, D.R. Ketten, J.H. Miller, P.E. Nachtigall, W.J. Richardson, J.A. Thomas and P.L. Tyack (2007). Marine mammal noise exposure criteria: Initial scientific recommendations, Aquatic Mammals, 33, 411-521.

Stone, C.J. (2000). Cetacean observations during seismic surveys in 1998, JNCC Report, No. 301.

Stone, C.J., and M.L. Tasker (2006). The effects of seismic airguns on cetaceans in UK waters, Journal of Cetacean Research and Management (JCRM), 8(3), 255-263.

Stone, C.J. (2015). Marine mammal observations during seismic surveys from 1994-2010, JNCC report, No. 463a.

Tringali, L.M., S. Floridia, V.I. Grasso, E. Internullo and C. Monaco (2008). Sulla conservazione dei Cetacei nel Mediterraneo, Convegno celebrativo per il $35^{\circ}$ anno di fondazione dell'Ente Fauna Siciliana, L'Area Protetta di Vendicari, October 25-26, 2008, Vendicari-Noto, Italy.

Vindigni, G., G. Carrà and C. Monaco (2016). Which approach for sustainable development of small-scale fisheries? The case of Italy, Quality - Access to Success, SRAC - Societatea Romana Pentru Asigurarea Calitatii, March 2016, 17, 142-148.

Weaver, A.C. (1987). An ethogram of naturally occurring behaviour of bottlenose dolphins, Tursiops truncatus, in Southern California waters, Master's thesis, San Diego State University, 180 p.

\footnotetext{
^Corresponding author: Clara Monaco,

Ketos Cultural Scientific Association, Catania, Italy; Università di Catania, Dipartimento di Agricoltura, Alimentazione e Ambiente, Catania, Italy; email: claramonaco@ketos.sicily.it, clamonaco@unict.it. 